\title{
Hyalesthes obsoletus is an active vector of Wood blackening in the Republic of Moldova
}

\author{
Evgeniy Haustov, and Victor Bondarciuc
}

Scientific and Practical Institute of Horticulture, Viticulture and Food Technologies, 59 str. Vierul, Chisinau, MD 2070, Moldova

\begin{abstract}
Hyalesthes obsoletus (Signoret) is an important vector of Wood Blackening in the Republic of Moldova. To identify the causes of the epidemiology of this disease in vineyards, the period of flight and the preference of the host plant $H$. obsoletus in the field were studied. Monitoring of vineyards showed that this species was found on the Field Bindweed (Convolvulus arvensis L.), and during the period of mass flight, the leafhopper was observed on Xanthium strumarium and Gorets bindweed (Fallopia convolvulus $L$.). The captured leafhoppers were diagnosed with the presence of Bois Noir stolbur phytoplasm (STOL). The adults of $H$. obsoletus were also caught from other herbaceous plants: Povoy fence (Calystegia sepium L.), Garden quinoa (Ariplex hortensis L.), Sow thistle (Sonchus oleraceus L.), Medicinal dandelion (Taraxacum officinale L.), as well as c Stinging nettle (Urtica dioica L.). Changes in climatic conditions in the region, causing premature drying of the grass cover, forces cicadas vectors to switch to actively growing plants during this period, including grapes, which contributes to the widespread of the disease.
\end{abstract}

\section{Introduction}

In the vineyards of Moldova, a disease of phytoplasmic etiology such as "jaundice" (yellows) has become widespread. The most famous representatives of this type of disease are Golden yellowing (Flavescence doree, FD - from French) and Blackening of wood (Bois noir, BN from French) showing identical symptoms on the affected vine. A characteristic sign of phytoplasmic damage to the vine is yellowing of the leaves and curling their edges downwards in whites and reddening in red grapes. The leaves become firm and brittle to the touch. The next distinguishing feature is the delay in the ripening of the vine. Affected shoots do not ripen and remain green until late autumn. Affected shoots, as a rule, do not yield because the inflorescences dry out and fall off. If the infection occurred at a later period, then the set berries wrinkle due to partial or complete dehydration of the bunches.

Under the natural conditions, leafhoppers are carriers of phytoplasmic diseases of grapes. Thus, the vector of FD grapes is the leafhopper Scaphoideus titanus (Ball). The insect lives and eats only on grapes, without causing any harm to the grape plant. Its harmfulness lies in the transfer of a dangerous disease. It is a highly mobile and efficient carrier that is largely responsible for the spread of Golden Yellowing. Therefore, FD, in the presence of a leafhopper Sc. titanus, can become epidemic. 
Vine disease transfer BN belonging to the species Ca. Phytoplasma solani - stolbur phytoplasma (STOL) and belongs to the ribosomal group - 16SrXII - A, is associated with the leafhopper $H$. obsoletus [1,2]. The grape plant is a random feeding place for the leafhopper [3-5]. The leafhopper transfers the stolbur phytoplasma to various weeds and cultivated herbaceous plants [6-8]. The transfer of phytoplasma by the vector is carried out as follows: the leafhopper, feeding on an infected plant, absorbs phytoplasma with plant juice, entering the food tract, and then into the body of the insect. Phytoplasma in the body of an insect acquires a latent form and incubates for 1 to 4 weeks. During this time, it multiplies and parasitizes most of the tissues and organs of the insect, then reaches the salivary glands. Starting from this period, the leafhopper, each time feeding on a healthy plant, infects it [9]. Phytoplasmas belonging to the $16 \mathrm{SrXII}$ - A group infects many cultivated plants [10]. In Europe, BN disease is transmitted to the grape plant from bindweed [6] and nettle $[11,12]$, however, with the growth of other weeds on plantations, cases of the spread of infection have been recorded $[13,14]$.

The high harmfulness of diseases of grapes of phytoplasma etiology necessitates a comprehensive study in order to develop effective control measures. To solve the problem, it is necessary: to identify the pathogen, to establish the vector of the disease and the factors contributing to the spread on the vineyards of the Republic of Moldova.

\section{Materials and methods}

The work was carried out in the Laboratory of Virology and Phytosanitary Control at the Institute of Horticulture, Viticulture and Food Technologies (IŞPHTA).

The objects of visual inspection were: plantations of European, autochthonous and new grape varieties, located in Kagulsky, Kantemirsky, Leovsky, Nisporensky, Ungensky, Teleneshtsky, Strashensky, Criulyansky, Novo-Anensky, Kaushansky, Stefan-Vodsky, Ceadir-Lungsky districts; diseases of the vine of phytoplasmic etiology FD and BN; leafhoppers - vectors of Sc. titanus and H. obsoletus.

Monitoring of cicadas was carried out by taking samples from plants located in vineyards and adjacent territories with a total area of more than 10 hectares in the Ialoveni and Kaushany districts, using a trapping net and an entomological aspirator, as well as using yellow sticky traps. Monitoring was carried out annually from May to September. The traps were changed and the entomological net $(30 \mathrm{~cm}$ in diameter) was caught every 10 days. Traps were installed both along the edges of the vineyards and in the center of the cages. Insects were caught, both from grape plants and from the grass cover in the vineyard and adjacent territories (height above the soil level 0-50 cm), one catch included 50 strokes.

The leafhoppers were photographed using a digital microscope camera. The leafhoppers were identified using the guides Anufriev G.A., Emelyanov A.F. 1988 and Wilson M. R. \& Turner, J. A. 2010.

DNA extraction from samples of leaves of grapes, weeds and insects was carried out according to the recommendations of the Scientific Research Center of Viticulture (CREA) Conegliano, Italy. The French official Duplex Nested End - Point PCR method, a commercial kit from Qualiplant, performed disease diagnosis. For the first amplification, primers were used: FD9f/FD9r and STOL11f2 / STOL11r1, for the second amplification: FD9r2/FD9f3b and STOL11f3 / STOL11r2.

\section{Results and discussion}

In the period from 2018-2020, expeditionary surveys of vine plantations were carried out on an area of about 800 hectares in all zones of its cultivation. The aim was to study the 
geography of the spread of phytoplasmic disease in vineyards and to take samples for testing and identification of the pathogen. Surveys were carried out from September to October. In white grape varieties (Chardonnay, Riesling, Sauvignon, Aligote, etc.) during this period, the leaves were golden-yellow in color, hard to the touch and curled downward. The leaves of the Chardonnay variety often showed necrotic spots, and the leaves themselves were twisted to such an extent that they had a triangular shape (Fig. 1).

Symptoms of the disease in varieties with red berries (Cabernet-Sauvignon, Merlot, Pinot black, Feteasca Neagra, Rara Neagra, Moldova, etc.) were observed in the form of reddening of the leaf blades. On the affected shoots, leaves were often found, on which reddening occupied only one sector, limited by two or three veins (Fig. 1). Diseased shoots were usually green, with no signs of ripening and no harvest. On shoots with symptoms, an unconditioned crop was observed, the berries were shriveled due to partial or complete dehydration.
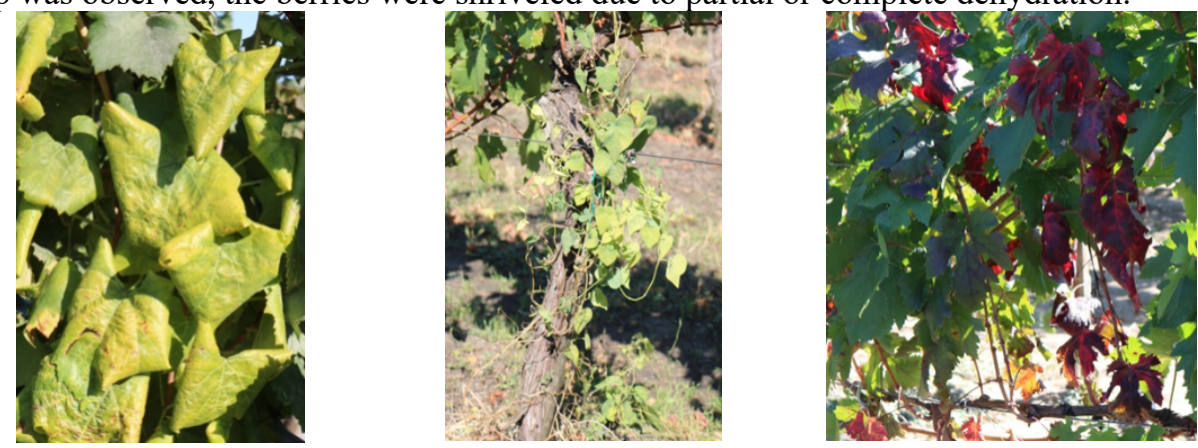

Fig 1. Symptoms of phytoplasmic lesions: on the left - on the leaves of the Chardonnay variety; in the center - on the Feteasca Neagra variety; on the right - on the Highlander bindweed (Fallópia convólvulus L.)

The defeat of vineyards by phytoplasmosis was established in all zones of grape cultivation. However, the intensity of manifestation on the bushes, the typicality and percentage of damage varied significantly. Particularly noteworthy is the defeat of autochthonous and new selection of grape varieties by phytoplasmosis. Thus, the defeat of the autochthonous grape variety Feteasca Neagra ranged from 9.4 to $28.3 \%$, and the Moldova variety from 8.4 to $36.0 \%$.

Leaf samples with disease symptoms were taken from each plantation surveyed for laboratory testing. During the survey period, 470 samples were collected and tested by the Nested PCR method, of which 256 were positive for the phytoplasm-pathogen BN, 214 samples were free of the pathogens FD and BN. The obtained results indicate the widespread prevalence of BN disease and the absence of FD. The establishment of imported seedlings can explain the presence of BN disease on plantations of European grape varieties; however, its wide distribution in natural conditions is possible only through an active carrier. This is confirmed by the appearance of the disease on autochthonous and new varieties of grapes.

Monitoring of vine plantations for vectors of phytoplasmic diseases revealed the presence of leafhoppers $H$. obsoletus. The flight of the imago took place from mid-June, and the flight lasted until August. Mass flight was observed in the first half of July. The preferred plant for the leafhopper H. obsoletus was the Field Bindweed (Convolvulus arvensis L.), however, during the period of mass flight, the leafhopper was observed on the Cocklebur (Xanthium strumarium L.) and the Bindweed (Fallopia convolvulus L.), as well as on: Povoe fence (Calystegia sepium L.), Garden swan (Ariplex hortensis L.), Ostota (Sonchus oleraceus L.), Dandelion (Taraxacum officinale L.) and Stinging nettle (Urtica dioica L.) (Fig. 2). 

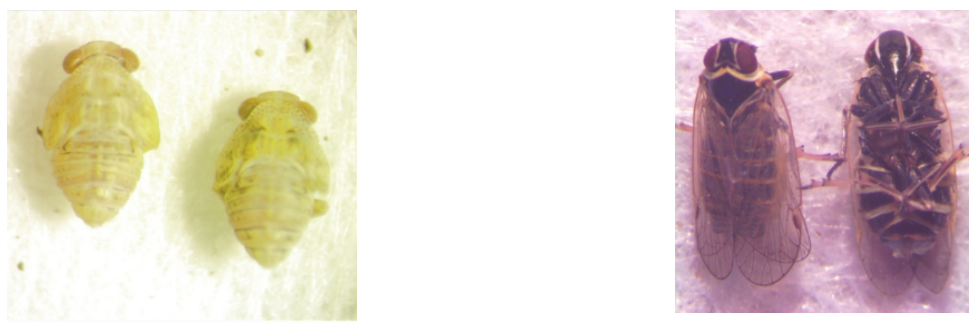

Fig 2. Left - 5th instar larvae of $H$. obsoletus. Right - adults of $H$. obsoletus - female, dorsal and ventral surface of the body

To establish a causal relationship between grapes, vectors and weeds, leafhoppers were caught from plants growing on vineyards and nearby areas. The captured leafhoppers were tested by the Nested PCR method for the presence of phytoplasmic pathogens FD and BN (Table 1).

Table 1. Results of testing H. obsoletus (Signoret) for the presence of phytoplasma Wood blackening

\begin{tabular}{|c|c|c|c|c|c|}
\hline \multirow[t]{3}{*}{ year } & \multirow[t]{3}{*}{ Flying leafhopper } & \multicolumn{4}{|c|}{ Number of individuals of Hyalesthes obsoletus } \\
\hline & & \multirow[t]{2}{*}{ Caught, pes. } & \multirow[t]{2}{*}{ Tested, pcs. } & \multicolumn{2}{|c|}{ Infected } \\
\hline & & & & pcs. & $\%$ \\
\hline 2018 & 12.06. -23.08 & 29 & 11 & 4 & 36.4 \\
\hline 2019 & 24.06. -20.08 & 53 & 7 & 3 & 42.9 \\
\hline 2020 & 15.06. - 13.08. & 21 & 7 & 3 & 42.9 \\
\hline
\end{tabular}

According to the test results, from 36.4 to $42.9 \%$ of the tested insects contained BN phytoplasm, which indicates the infectious state of plants included in the insect's life cycle. Phytoplasm Stolbur (Ca. Phytoplasma solani, 16SrXII), which causes BN disease on the vine, was previously found in herbaceous weeds, such as Field Bindweed, Highlander Bindweed, Mary's whole-leaved, as well as in Rose and Elm, which allowed them to be attributed to reserve plants phytoplasma [15]. The life cycle of the insect $H$. obsoletus is mainly associated with weeds. The female lays eggs in August in the soil at the base of the stem of the host plant (Fig.3).

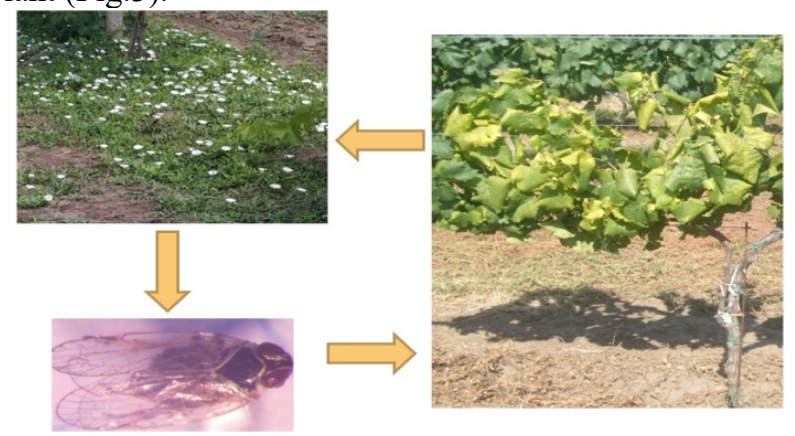

Fig. 3. BN phytoplasma infection cycle

The hatched larvae feed on the roots of the host plant. If the plant is a reserve of phytoplasma, then the larvae, feeding on the roots of this plant, acquire phytoplasma and become viroform. Imagoes formed from viroform larvae are also viroform. It should be noted that in the Republic of Moldova, over the past 10-15 years, there has been significant climate change. According to meteorological observations over the past four years (2017-2020), the average annual air temperature has increased by $2.2^{\circ} \mathrm{C}$ compared to the average annual data 
of previous years. At the same time, with an increase in temperature, there is a decrease in the amount of precipitation by $147.3 \mathrm{~mm}$. These climatic changes led to the fact that starting from the second half of June, the daytime air temperature increased to $35-37^{\circ} \mathrm{C}$, and the amount of precipitation decreased accordingly. High air temperature and moisture deficit in the soil negatively affect the condition of the herbaceous cover. Plants age quickly, turning yellow, and dry out, which forces the polyphagous leafhopper to switch to other food sources. For leafhoppers-polyphagous one of such food sources is a grape plant, which actively develops during this growing season, forming numerous stepsons. Viroform leafhoppers, feeding on the juice of young and succulent shoots, infect them with phytoplasma. Thus, the existing climatic conditions have become one of the decisive factors contributing to the accelerated spread of $\mathrm{BN}$ disease on vine plantations.

\section{Conclusion}

A survey of more than 800 hectares of grape plantations in all cultivation areas revealed the defeat of European, autochthonous and new varieties of the disease of phytoplasmic etiology. Nested PCR testing of 470 samples of leaves with symptoms of the disease showed the presence of phytoplasma - the causative agent of BN and the absence of FD. Nested PCR testing revealed stolbur phytoplasm (Ca. Phytoplasma solani, 16SrXII) in leafhoppers of $H$. obsoletus. On average, $40 \%$ of adults of $H$. obsoletus were viroform, which indicates the infectious state of plants entering the insect's life cycle. Under conditions of the Republic of Moldova, Field bindweed (Convolvulus arvensis L.), Eurasian cocklebur (Xanthium strumarium L.), and Bindweed (Fallopia convolvulus L.) are reserves of BN phytoplasm and contribute to its spread, premature drying of the grass cover, which forces insects to switch to other actively growing plants, including grapes during this period of the growing season.

\section{References}

1. S. Murolo, M. Garbarino, V. Mancini, Sci. Rep., 10, 9801 (2020) https://doi.org/10.1038/s41598-020-66210-7

2. E. Şimşek, M. Güldür, Harran Tarım ve Gıda Bilimleri Dergisi, 25(2), 204-213 (2021) http://doi.org/10.29050/harranziraat.816630

3. M. Sargolzaei, L. Rustioni, G. Cola, V. Ricciardi, P.A. Bianco, D. Maghradze, O. Failla, F. Quaglino, S.L. Toffolatti, G. De Lorenzis, Front. Plant Sci., 12, 630122 (2021) http://doi.org/10.3389/fpls.2021.630122

4. C. Olivier, C. Vincent, J. Saguez, B. Galka, P.G. Weintraub, M. Maixner, In: N.J. Bostanian, C. Vincent, R. Isaacs (eds) Arthropod Management in Vineyards, 253-270 (Springer, Dordrecht, 2012) https://doi.org/10.1007/978-94-007-4032-7 11

5. A. Kosovac, J. Johannesen, O. Krstić, M. Mitrović, T. Cvrković, I. Toševski, J. Jović, PLOS ONE, 13(5), e0196969 (2018) https://doi.org/10.1371/journal.pone.0196969

6. N. Mori, E. Cargnus, M. Martini, F. Pavan, Insects, 11(9), 606 (2020) https://doi.org/10.3390/insects11090606

7. B. Panassiti, M. Breuer, S. Marquardt, R. Biedermann, Bulletin of Entomological Research, 103(6), 621-633 (2013) http://doi.org/10.1017/S0007485313000163

8. J. Mitovic, B. Duduk, Bull. Insect., 64, 107-108 (2011) https://www.researchgate.net/publication/267264445

9. G.M. Gurr, A.C. Johnson, G.J. Ash, B.A.L. Wilson, M.M. Ero, C.A. Pilotti, C.F. $\begin{array}{lllllll}\text { Dewhurst, } & \text { M.S. You, Front. Plant } & \text { Sci., 7, } 1521 & \text { (2016) }\end{array}$ $\underline{\text { http://doi.org/10.3389/fpls.2016.01521 }}$ 
10. M. Cheng, J. Dong, I.M. Lee, K.D. Bottner-Parker, Y. Zhao, R.E. Davis, P.J. Laski, Z. Zhang, J.H. McBeath, Eur. J. Plant Pathol., 142, 305-318 (2015) https://doi.org/10.1007/s10658-015-0616-9

11. A. Bertaccini, B. Duduk, S. Paltrinieri, N. Contaldo, Am. J. Plant Sci., 5(12), 46299 (2014) http://doi.org/10.4236/ajps.2014.512191

12. M. Maixner, Recent advances in Bois Noir research, Petria, 21, 85-190 (2011)

13. C. Oliveri, D. Pacifico, V.D’Urso, R. La Rosa, C. Marzachì, M. Tessitori, Australian Plant Pathol., 44, 235-244 (2015) https://doi.org/10.1007/s13313-014-0342-3

14. A. Kosovac, S. Radonjic, S. Hrncic, O. Krstic, I. Tosevski, J. Jovic, Plant Pathol., 65, 285-298 (2016) https://doi.org/10.1111/ppa.12409

15. V.V. Bondachuk, E.I. Haustov, Russian Grape, 14, 51-59 (2020) http://doi.org/10.32904/2712-8245-2020-14-51-60 